\title{
Perceptions of Healthcare Professionals on COVID-19 in Lesotho: A Cross-Sectional Survey
}

\author{
Isabel Nyangu ${ }^{1 *}$, Maseabata Ramathebane ${ }^{2}$ \\ ${ }^{1}$ Department of Nursing, National University of Lesotho, Roma, Lesotho \\ ${ }^{2}$ Department of Pharmacy, National University of Lesotho, Roma, Lesotho \\ Email: ^4321bellah@gmail.com, mvramathebane@gmail.com
}

How to cite this paper: Nyangu, I. and Ramathebane, M. (2022) Perceptions of Healthcare Professionals on COVID-19 in Lesotho: A Cross-Sectional Survey. Journal of Biosciences and Medicines, 10, 39-50. https://doi.org/10.4236/jbm.2022.102005

Received: January 5, 2022

Accepted: February 8, 2022

Published: February 11, 2022

Copyright () 2022 by author(s) and Scientific Research Publishing Inc. This work is licensed under the Creative Commons Attribution International License (CC BY 4.0).

http://creativecommons.org/licenses/by/4.0/ (c) (i) Open Access

\begin{abstract}
Background: Health care professionals at the front line of the COVID-19 pandemic require continued support to ensure not only their well-being, but enhanced care for those infected by the disease. This study aimed to assess the perceptions of health care providers regarding the COVID-19 pandemic in Lesotho. Methodology: A quantitative cross-sectional survey design was used to collect data from 190 healthcare workers who were conveniently sampled from a total of 25 health care facilities and completed structured questionnaires. Data were collected in September 2021 and analyzed using SPSS (vs23). Permission to conduct this study was granted by the relevant authorities. Informed written consent was given by the respondents in writing before they could take part in this study. Results: Respondents had positive views about the COVID-19 pandemic, and they were associated with the level of education. They understood that COVID-19 can affect anyone, including themselves and is not a disease for any particular race. They perceived that they could contract COVID-19, even despite pre-existing conditions, and there was a positive prognosis after contracting COVID-19 if necessary precautions were taken. Furthermore, they knew that the virus was affecting many people worldwide, including the elderly, who were willing to be tested. Respondents felt the testing procedure was rather painful and uncomfortable. The test providers were friendly and not rude, and respondents did not have any preferred gender for them. Respondents were also willing to discuss issues on COVID-19 with families and friends, and they lived close to health care facilities. Conclusions: This study concludes that healthcare professionals at the frontline were mostly nurses, and they had positive perceptions about the COVID-19 pandemic as they were knowledgeable and willing to test for the disease. Test providers were viewed as pleasant and healthcare facilities were
\end{abstract}


accessible. Support for frontline healthcare professionals remains crucial to ensure effective service delivery. More education can be provided to enhance the general views about the COVID-19 to improve uptake of services, not only amongst healthcare professionals but the general public.

\section{Keywords}

COVID-19, Perceptions, Healthcare Professionals, Lesotho

\section{Introduction}

The COVID-19 pandemic has been most devastating worldwide, causing medical, social, and economic impacts and posing significant challenges for health care professionals [1] and vulnerable populations such as the poor, girls, and rural communities who are exposed to educational inequalities due to the pandemic [2]. The SARS CoV-2 continues to mutate, further posing threats to the well-being of health care workers on the frontline. To preserve healthcare professionals who are highly susceptible to infection, to continue providing treatment, care, and support of COVID-19 patients and those suffering from other diseases, they must be provided with personal protective equipment (PPE) [3]. The implementation of enforced physical distancing, increasing the availability of PPEs, and proper guidelines would significantly reduce transmission rates and help save lives [4].

The physical and psychological well-being of the healthcare professionals are being tested as patient loads tend to increase significantly and fellow co-workers become infected with COVID-19, contributing significantly to burnout [5] [6]. Burnout has been reported in the form of emotional exhaustion, depersonalization, and low personal accomplishment [6]. Thus, it is very important to engage productive strategies to care for the mental health of healthcare professionals. The number of healthcare professionals infected and dying continues to rise; hence, the number of providers continues to diminish. Additionally, many healthcare professionals have lost their lives due to COVID-19 worldwide. The effects of this increase in workload in the dangerous atmosphere of this pandemic are the decline in the mental health of the healthcare professionals [5] [7].

Additionally, healthcare professionals have had to self-isolate from their own families for fear of transmitting the virus to them [7], as there is guilt when a family member becomes infected. Social isolation, exposure to prolonged quarantine, the fear of infecting or having infected their family, and uncertainties with critically ill patients contributed to higher rates of stress-related illness amongst health care workers [6]. The healthcare professionals are bravely living in a constant state of psychological stress founded on fear; fear of transmitting the virus and stress of the unknown aspects of this virus. This study, therefore, sought to determine the perceptions of healthcare professionals on COVID-19 in Lesotho. 


\section{Methods}

This study aimed to assess the perceptions of health care professionals regarding the COVID-19 pandemic in Lesotho.

\subsection{Research Design}

A quantitative cross-sectional survey design was used to collect data from a sample of 190 healthcare professionals who were conveniently sampled from a total of 25 health care facilities that were from the districts of Thaba Tseka, Butha Buthe, Leribe, Berea, Maseru, Mafeteng, and Quthing. Data were collected at 12 hospitals and 13 health center clinics from a sample of nurses, doctors, pharmacists, laboratory scientists/technicians, dentists, counselors, and administrative assistants. A total of 255 structured questionnaires were distributed and 190 of them were returned completed (75\% response rate).

\subsection{Data Collection}

A semi-structured questionnaire developed by the researchers following an extensive literature review was used to collect data. A pre-test of the data collection tool was done on a sample of 10 respondents to ascertain validity and reliability. Data were collected in September 2021 by trained data collectors and analyzed using SPSS (vs23). It is presented using tables, graphs, proportions, and Chi square test results.

\subsection{Ethical Considerations}

Permission to conduct this study was granted by the National University of Lesotho Institutional Review Board and the Lesotho Ministry of Health Research and Ethics Committee (ID20-2021). Written informed consent was given by the participants in writing before they could take part in this study. All information about the study was availed to the respondents who were identified using codes and voluntarily took part in the study. They could ask clarity-seeking questions and could withdraw from the study without any repercussions.

\section{Results}

\subsection{Study Site}

Five per cent $(\mathrm{n}=9)$ of the respondents were from Butha Buthe hospital, 6.5\% (n = 11) from Berea hospital, 5.8\% $(\mathrm{n}=10)$ from Maluti Adventist Hospital, 7\% ( = 12) from Motebang hospital, 7.6\% $(\mathrm{n}=13)$ from Ntsekhe hospital, 5.8\% $(\mathrm{n}=$ 10) from Mafeteng hospital, 5.8\% $(\mathrm{n}=10)$ from Scott Hospital, $1.8 \%(\mathrm{n}=3)$ from Seboche Hospital, 1.8\% $(\mathrm{n}=3)$ from St. James Hospital, and 5.3\% $(\mathrm{n}=9)$ from Makoanyane Military hospital. Data were also collected from health centres. 2.9\% $(\mathrm{n}=5)$ of the respondents were from Domiciliary clinic, 3.5\% $(\mathrm{n}=6)$ from Holy Cross clinic, 2.9\% ( $\mathrm{n}=5)$ from LDF, $2.9 \%(\mathrm{n}=5)$ from Le Coop clinic, 2.3\% $(\mathrm{n}=4)$ from Likalaneng clinic, $2.9 \%(\mathrm{n}=5)$ from Likotsi filter clinic, $2.9 \%(\mathrm{n}=5)$ from Maputsoe filter clinic, $1.2 \%(\mathrm{n}=2)$ from Marakabei clinic, 
1.8\% $(\mathrm{n}=3)$ from Morifi clinic, $1.8 \%(\mathrm{n}=3)$ from Motsekuoa clinic, $2.9 \%(\mathrm{n}=$ 5) from Qoaling filter clinic, $1.8 \%(\mathrm{n}=3)$ from Tsepo clinic, and $2.3 \%(\mathrm{n}=4)$ from Villa Maria clinic.

\subsection{Demographic Data}

The minimum age was 20 years and the maximum age was 64 (Range $=44)$. The mean age was 36 years $( \pm 9)$. Respondents had a minimum of zero children and a maximum of four (Range $=4)$. The mean number of children was $1( \pm 1)$. There were $78 \%(n=143)$ females and $22 \%(n=40)$ males. Twenty-three per cent $(n=$ 43 ) of the respondents were single or never married, $55 \%(n=107)$ were married, $3 \%(n=6)$ were separated, $3 \%(n=5)$ were widowed, $4 \%(n=8)$ were divorced, $3 \%(n=6)$ did not provide an answer, whilst $7 \%(n=13)$ preferred not to say. Majority, (91\%: $n=173)$ of the respondents were Christian, $1 \%(n=1)$ worshiped in African Tradition, $1 \%(n=1)$ were Hindu, $4 \%(n=8)$ did not provide their religion, whilst $3 \%(n=6)$ selected none. The majority $(93 \% ; n=177)$ of the respondents were employed, $1 \%(n=2)$ were either students, retrenched, retired, unemployed, or volunteered, whilst $4 \%(n=7)$ did not provide an answer.

\subsection{Occupation Type}

The majority (44\%: $n=84$ ) of the respondents were registered nurse midwives, $8 \%(n=16)$ were nursing assistants, $8 \%(n=15)$ were laboratory technicians, $8 \%$ $(n=16)$ were pharmacy technicians, $4 \%(n=8)$ were medical doctors, $6 \%(n=$ 11) were counselors, whilst the remaining were in the remaining categories as shown in Table 1.

\subsection{Perceptions on COVID-19}

When asked if COVID-19 is a disease for other people, the majority $(79 \% ; \mathrm{n}=$ $150)$ of the respondents strongly disagreed, $16 \%(n=31)$ disagreed, $3 \%(n=6)$ did not answer, whilst less than $1 \%(n=1)$ either were not sure, agreed or strongly agreed. The perceptions on whether COVID-19 is a disease for other people and not Basotho were associated with the level of education $\left[\mathrm{X}^{2}(35, \mathrm{~N}=\right.$ 190) $=140.13, \mathrm{p}<0.05]$.

The majority of the respondents feared contracting COVID-19 due to an existing condition as $31 \%(\mathrm{n}=60)$ strongly disagreed, $26 \%(\mathrm{n}=49)$ disagreed, $23 \%$ $(\mathrm{n}=44)$ agreed, $8 \%(\mathrm{n}=15)$ strongly agreed, $8 \%(\mathrm{n}=15)$ were not sure, whilst $4 \%(n=7)$ did not answer. The perceptions on whether they feared to contract COVID-19 due to an existing condition were associated with the level of education $\left[\mathrm{X}^{2}(42, \mathrm{~N}=190)=135.32, \mathrm{p}<0.05\right]$. The majority of the respondents "could not believe they can contract COVID-19" as $36 \%(n=68)$ strongly disagreed, $35 \%(n=66)$ disagreed, $15 \%(n=29)$ were not sure, $7 \%(n=13)$ agreed, $3 \%(n=6)$ strongly agreed, whilst $4 \%(n=8)$ did not answer. The perceptions on whether they could not believe they can contract COVID-19 were associated with the level of education $\left[\mathrm{X}^{2}(35, \mathrm{~N}=190)=99.78, \mathrm{p}<0.05\right]$. 
Table 1. Occupation type.

\begin{tabular}{|c|c|c|}
\hline \multicolumn{3}{|c|}{ Occupation type } \\
\hline Occupation & Frequency & Percent \\
\hline No Answer & 6 & 3.2 \\
\hline CLEANER & 3 & 1.6 \\
\hline COUNSELOR & 11 & 5.8 \\
\hline COVID-19 SCREENER & 1 & 0.5 \\
\hline DATA CLERK & 3 & 1.6 \\
\hline DENTIST & 1 & 0.5 \\
\hline DOCTOR & 8 & 4.2 \\
\hline HEAD MEDICAL BRANCH & 1 & 0.5 \\
\hline HEALTH ASSISTANT & 5 & 2.6 \\
\hline LABORATORY TECHNICIAN & 15 & 7.9 \\
\hline MENTOR MOTHER & 2 & 1.1 \\
\hline N/A & 1 & 0.5 \\
\hline NURSING ASSISTANT & 16 & 8.4 \\
\hline PHARMACY TECHNICIAN & 16 & 8.4 \\
\hline PSYCHOSOCIAL SUPPORT & 2 & 1.1 \\
\hline PUBLIC RELATION OFFICER & 1 & 0.5 \\
\hline REGISTERED NURSE/ MIDWIFE & 84 & 44.2 \\
\hline RETENTION OFFICER & 2 & 1.1 \\
\hline SITE COORDINATOR & 1 & 0.5 \\
\hline SOCIAL WORKER & 2 & 1.1 \\
\hline STUDENT NURSE & 2 & 1.1 \\
\hline TB \& COVID CONTACT & 3 & 1.6 \\
\hline WARD ATTENDANT & 3 & 1.6 \\
\hline YOUTH AMBASSADOR & 1 & 0.5 \\
\hline Total & 190 & 100.0 \\
\hline
\end{tabular}

The majority of the respondents $(38 \% ; \mathrm{n}=73)$ disagreed that "they feared to be amongst COVID-19 statistics and checked the world odometer daily", 16\% (n $=30)$ strongly disagreed, $24 \%(\mathrm{n}=45)$ agreed, $14 \%(\mathrm{n}=26)$ strongly agreed, $3 \%$ $(n=6)$ were not sure, whilst $5 \%(n=9)$ did not answer the question. The perceptions on whether they feared to be amongst COVID-19 statistics and checked the world odometer daily were associated with the level of education [X2 (42, N $=190)=122.73, \mathrm{p}<0.05]$. The majority, $37 \%(\mathrm{n}=70)$ strongly disagreed that "they did not want to test for COVID-19", 25\% $(\mathrm{n}=48)$ disagreed, $5 \%(\mathrm{n}=10)$ 
were not sure, $18 \%(n=35)$ agreed, $11 \%(n=20)$ strongly agreed, whilst $4 \%(n=$ 7 ) did not answer the question. The perceptions on whether they did not want to test for COVID-19 were associated with the level of education $\left[\mathrm{X}^{2}(42, \mathrm{~N}=190)\right.$ $=149.96, \mathrm{p}<0.05]$.

The majority, 36\% $(n=68)$ of the respondents strongly disagreed that "they could not believe they can contract COVID-19", 35\% $(\mathrm{n}=66)$ disagreed, $15 \%(\mathrm{n}$ $=29)$ were not sure, $7 \%(n=13)$ agreed, $3 \%(n=6)$ strongly agreed, whilst $4 \%$ $(n=8)$ did not provide an answer. Perceptions on if they could not believe they can contract COVID-19 were associated with the level of education $\left[\mathrm{X}^{2}(35, \mathrm{~N}=\right.$ $190)=99.78, \mathrm{p}<0.05]$. The majority $49 \%(\mathrm{n}=94)$ of the respondents strongly disagreed that "they would not live after contracting COVID-19", 27\% ( $n=51)$ disagreed, $15 \%(n=28)$ were not sure, $3 \%(n=6)$ agreed, $2 \%(n=4)$ strongly agreed, $3 \%(n=6)$ did not answer, whilst $1 \%(n=1)$ said the question was not applicable. Perceptions on whether they thought they would not live after contracting COVID-19 were associated with the level of education $\left[\mathrm{X}^{2}(42, \mathrm{~N}=190)\right.$ $=140.88, \mathrm{p}<0.05]$.

The majority $44 \%(\mathrm{n}=83)$ of the respondents strongly disagreed that "they felt the COVID-19 test takes too much time", 38\% $(n=72)$ disagreed, $5 \%(n=9)$ were not sure, $5 \%(n=9)$ strongly agreed, $5 \%(n=10)$ agreed, whilst $3 \%(n=6)$ did not provide an answer. Perceptions on whether the COVID-19 test takes too much time were associated with the level of education $\left[\mathrm{X}^{2}(42, \mathrm{~N}=190)=145.0\right.$, $\mathrm{p}<0.05]$. When asked if COVID-19 test is too painful, $29 \%(\mathrm{n}=55)$ of the respondents agreed, $18 \%(\mathrm{n}=35)$ strongly agreed, $23 \%(\mathrm{n}=43)$ disagreed, $12 \%(\mathrm{n}$ $=23)$ strongly disagreed, $14 \%(n=27)$ were not sure, $3 \%(n=6)$ did not answer, whilst $1 \%(n=1)$ said the question was not applicable. The perceptions on whether the COVID-19 test is painful were associated with the level of education $\left[\mathrm{X}^{2}(42, \mathrm{~N}=190)=146.56, \mathrm{p}<0.05\right]$.

When asked whether or not COVID-19 test providers are rude to men and women, $45 \%(n=88)$ of the respondents strongly disagreed, $31 \%(n=59)$ disagreed, $10 \%(n=19)$ were not sure, $6 \%(n=11)$ strongly agreed, $3 \%(n=6)$ agreed, $3 \%(n=6)$ did not answer, whilst $1 \%(n=1)$ said the question was not applicable. The perceptions on whether COVID-19 test providers were rude to men and women were associated with the level of education of the respondents $\left[\mathrm{X}^{2}(49, \mathrm{~N}=190)=146, \mathrm{p}<0.05\right]$. When asked if they had other problems other than COVID-19, 32\% $(\mathrm{n}=61)$ of the respondents strongly disagreed, $37 \%(\mathrm{n}=$ 70 disagreed, $12 \%(\mathrm{n}=23)$ agreed, $7 \%(\mathrm{n}=14)$ strongly agreed, $7 \%(\mathrm{n}=14)$ were not sure, $4 \%(n=7)$ did not answer, whilst $1 \%(n=1)$ said the question was not applicable. The perception on whether they had other problems other than COVID-19 were associated with their level of education $\left[X^{2}(49, N=190)=\right.$ 112.07, $\mathrm{p}<0.05$ ].

When asked if they felt they were too old to have COVID-19, majority (76\%; $\mathrm{n}$ $=144)$ of the respondents strongly disagreed, $18 \%(\mathrm{n}=34)$ disagreed, $1 \%(\mathrm{n}=2)$ strongly agreed, $1 \%(n=2)$ were not sure, $3 \%(n=6)$ did not answer whilst 15 $9 n=10$ said the question was not applicable. The perceptions on whether they 
felt they were too old to have COVID-19 were associated with the respondents' level of education $\left[\mathrm{X}^{2}(42, \mathrm{~N}=190)=132.29, \mathrm{p}<0.05\right]$.

The majority $(35 \% ; n=67)$ strongly agreed that "there was a health centre facility close to their house", $30 \%(\mathrm{n}=57)$ agreed, $21 \%(\mathrm{n}=40)$ disagreed, $8 \%(\mathrm{n}=$ 15) strongly disagreed, $2 \%(n=3)$ were not sure, whilst $4 \%(n=7)$ did not answer. The perceptions on the existence of a health centre close to their house were associated with the respondents' level of education $\left[X^{2}(42, N=190)=\right.$ $112.51, \mathrm{p}<0.05]$.

The majority, (36\%; $\mathrm{n}=69)$ agreed that "the COVID-19 test will not prevent their destiny to develop the disease", $13 \%(\mathrm{n}=24)$ strongly agreed, $13 \%(\mathrm{n}=25)$ were not sure, $11 \%(\mathrm{n}=20)$ strongly disagreed, $20 \%(\mathrm{n}=39)$ disagreed, $6 \%(\mathrm{n}=$ 11) did not answer whilst $1 \%(\mathrm{n}=2)$ said the question $\mathrm{a}=$ was not applicable. The perceptions of whether the COVID-19 test will not prevent their destiny to acquire the disease were associated with their level of education $\left[\mathrm{X}^{2}(49, \mathrm{~N}=\right.$ $190)=111.2, \mathrm{p}<0.05]$. When asked if they preferred a female health worker, a majority $(38 \%: \mathrm{n}=71)$ of the respondents disagreed, $37 \%(\mathrm{n}=71)$ strongly disagreed, $12 \%(\mathrm{n}=23)$ were not sure, $7 \%(\mathrm{n}=140)$ agreed, $2 \%(\mathrm{n}=4)$ strongly agreed, $3 \%(\mathrm{n}=4)$ did not answer, whilst $1 \%(\mathrm{n}=1)$ said the question was not applicable. The perceptions on whether they preferred a female health worker were associated with the respondents' level of education $\left[\mathrm{X}^{2}(42, \mathrm{~N}=190)=\right.$ 133.74, $\mathrm{p}<0.05]$.

When asked if they would never pay for the COVID-19 test if a payment was needed, a majority $(38 \% ; n=73)$ of the respondents disagreed, $31 \%(n=58)$ strongly disagreed, $13 \%(\mathrm{n}=25)$ agreed, $9 \%(\mathrm{n}=18)$ strongly agreed, $5 \%(\mathrm{n}=$ 9) were not sure, $3 \%(\mathrm{n}=6)$ did not answer, whilst $1 \%(\mathrm{n}=1)$ said the question was not applicable. The perceptions on whether they would not pay for a COVID-19 test if a payment was required were associated with their level of education $\left[\mathrm{X}^{2}(42, \mathrm{~N}=190)=131.48 . \mathrm{p}<0.05\right]$. On the question that said anyone can develop COVID-19, a majority $(52 \% ; \mathrm{n}=99)$ of the respondents strongly agreed, $36 \%(\mathrm{n}=69)$ agreed, $5 \%(\mathrm{n}=9)$ strongly disagreed, $2 \%(\mathrm{n}=4)$ disagreed, $1 \%(\mathrm{n}=2)$ were not sure, $3 \%(\mathrm{n}=5)$ did not answer, whilst $1 \%(\mathrm{n}=$ 1) said the question was not applicable. The perceptions on whether anyone can develop COVID-19 were associated with the level of education of the respondents $\left[\mathrm{X}^{2}(49, \mathrm{~N}=190)=126.7, \mathrm{p}<0.05\right]$.

On the question that said COVID-19 is a disease for the Chinese and not Basotho, a majority $(79 \% ; \mathrm{n}=151)$ of the respondents strongly disagreed, $15 \%(\mathrm{n}=$ 20) disagreed, $3 \%(\mathrm{n}=6)$ did not answer the question, $1 \%(\mathrm{n}=1)$ agreed, $1 \%(\mathrm{n}$ $=2)$ were not sure, whilst $1 \%(\mathrm{n}=1)$ said the question was not applicable. The perceptions on whether COVID-19 is a disease for the Chinese and not Basotho were associated with the respondents' level of education $\left[X^{2}(35, N=190)=\right.$ $107.69, \mathrm{p}<0.05]$. When asked if it was embarrassing to talk to family and friends about COVID-19, a majority $(60 \% ; n-132)$ of the respondents strongly disagreed, 25\% $(\mathrm{n}=47)$ disagreed, $1 \%(\mathrm{n}=2)$ strongly agreed, $1 \%(\mathrm{n}=2)$ were not sure, $3 \%(n=6)$ did not answer, whilst $1 \%(n=1)$ said the question was not ap- 
plicable. The perceptions on whether it is embarrassing to talk about COVID-19 were associated with the respondents' level of education $\left[\mathrm{X}^{2}(42, \mathrm{~N}=190)=\right.$ 132.19, $\mathrm{p}<0.05$ ] (Figure 1).

\section{Discussion}

In this study, majority of the health care professionals were nurses. This is in line with a previous study by Nyangu and Nkosi [8] who reported that majority of the health care facilities in Lesotho are staffed by registered nurse-midwives and nurse clinicians. Alhofaian et al. [9] also reported that the majority of the respondents in their study were nurses. As they form the majority of health care providers not only in Lesotho but the world over, it is important to provide the much-needed support in capacity building to reduce current existing gaps [10] and improve service delivery during the COVID-19 pandemic.

In this study, the level of education was found to be associated with positive perceptions of the respondents on the COVID-19 pandemic. In contrast, in a study by Bhagavathula et al. [11] age and profession were associated with inadequate knowledge and poor perceptions about COVID-19. This difference between the studies could be attributed to the time difference in which they were conducted, as at the end of 2021 more knowledge has been shared on the pandemic as compared to 2020. Healthcare professionals generally had positive views about the COVID-19 pandemic. This is in line with Bhagavathula et al. [11] who reported positive perceptions on COVID-19 amongst healthcare workers in Iran and in contrast to a study by Turktemiz et al. [12] who reported negative perceptions about COVID-19 amongst the study sample.

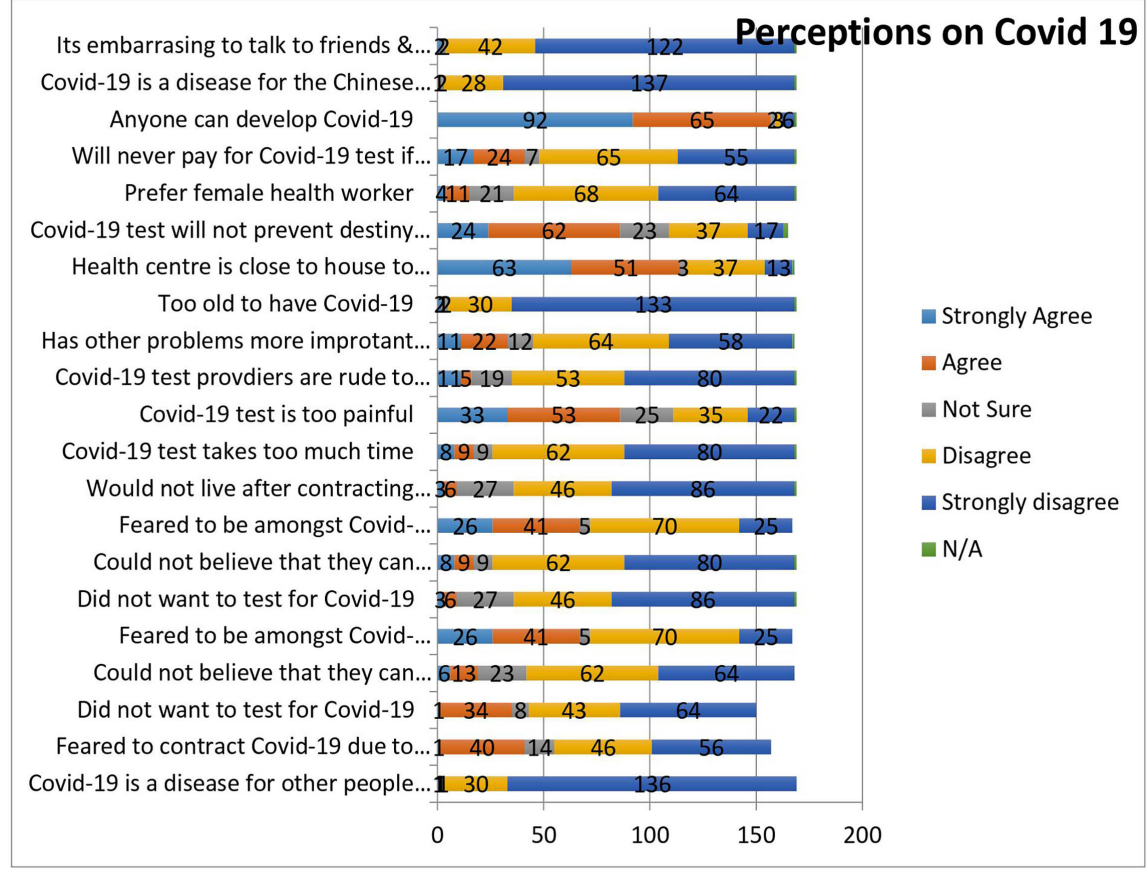

Figure 1. Health professionals' perceptions on COVID-19. 
As they are frontline workers, healthcare professionals must learn about and be aware of emerging knowledge regarding the COVID-19 pandemic [1]. In this study, they had the necessary knowledge to understand that COVID-19 could affect anyone, including themselves and is not a disease for any particular race. They were also aware that they could contract COVID-19, even despite pre-existing conditions. This shows positive views towards understanding that the disease can affect anyone, therefore, precautions remain paramount to prevent infection. This is in line with a study by Turktemiz et al. [12] who reported that healthcare professionals considered that they would be infected by COVID-19. Wang et al. [13] reported that it was a normal consequence that health care professionals believed they would be infected as they were in contact with infected patients. Respondents were also aware that there was a positive prognosis after contracting COVID-19 if necessary precautions were taken. Bhagavathula et al. [13] reiterated that most of the participants had positive perceptions on the prevention and control of COVID-19.

Respondents in this study knew that the virus was affecting many people worldwide, including the elderly, and were willing to take the test. This is in line with a study by Tao et al. [14] who reported that massive and rapid testing remains important for containing the spread of the COVID-19. Al Ghafri et al. [6] in their study stated that willingness to change was key to effective responses to COVID-19 and wisdom was derived from the many lessons learned daily from the pandemic. Even though the COVID-19 test was viewed not to take too much time, respondents felt that it is rather painful and uncomfortable. They, too, did not mind having to pay for the test if asked to do so. Similarly, Alhofaian et al. [9] reported that the success of the COVID-19 vaccination program was dependent on the public's acceptance and willingness to get the vaccines.

The test providers were friendly and not rude, and respondents did not have any preferred gender of the test providers. In this study, respondents were also willing to discuss issues on COVID-19 with families and friends. This is important to maintain communication and support for those infected and affected by the pandemic. Additionally, Wittenberg et al. [15] reiterated that communication enhancers were amongst the team, patients, family and also considered time and available training materials. The majority of the respondents lived close to health care facilities, an observation crucial for the accessibility of the healthcare services during the pandemic. This is in line with a study by Zhou et al. [16] who reported that access to medical resources may determine effective diagnosis and treatment. However, more efforts are crucial to reach the populations vulnerable to the pandemic, including the elderly [14].

\section{Conclusion}

This study concludes that health care professionals in Lesotho had positive perceptions about the COVID-19 pandemic in Lesotho. Health care providers at the frontline were mostly nurses, they were knowledgeable about the pandemic, and 
were willing to test for the disease. They felt that the test providers were pleasant and were able to access healthcare services as the facilities were proximal. With this in light of Lesotho as a developing country shows positive progress towards fighting the pandemic.

\section{Recommendations}

Support for health care professionals at the front line of the COVID-19 pandemic remains crucial to ensure effective service delivery. More education can be provided to improve the general views about the COVID-19 to improve uptake of services not only amongst health care providers but the general public as well.

\section{Limitations}

This study was limited to the perceptions of healthcare professionals on COVID-19 in Lesotho.

\section{Acknowledgements}

We acknowledge all healthcare professionals to take time to respond to the questionnaire amid their busy work schedules during the COVID-19 pandemic.

\section{Authors Contributions}

IN prepared the initial manuscript, analyzed and interpreted the data, and reviewed the manuscript before submission.

MR reviewed the initial manuscript, analyzed and interpreted the data, and reviewed the manuscript before submission.

\section{Conflicts of Interest}

The authors declare no conflicts of interest regarding the publication of this paper.

\section{References}

[1] Abdulwahab, M., Kamal, M., Alali, A.M., Husain, Y.M. and Safar, M. (2021) Knowledge and Perceptions of COVID-19 among Health Care Professionals, Medical Students, and Dental Students in the GCC Region: A Cross-Sectional Correlational Study. Journal of Multidisciplinary Healthcare, 14, 1223-1232. https://doi.org/10.2147/JMDH.S306324

[2] Herring, E., Campbell, P., Elmi, M., Ismail, L., McNeill, S., Rubac, A., Ali, A., Saeed, A. and Shidane, M. (2020) COVID-19 Responses and Education in Somalia/Somaliland. Sociology Mind, 10, 200-221. https://doi.org/10.4236/sm.2020.104013

[3] Nguyen, L.H., Drew, D.A., Graham, M.S., Joshi, A.D., Guo, C.G., Ma, W., Mehta, R.S., Warner, E.T., Sikavi, D.R., Lo, C.H., Kwon, S., Song, M., Mucci, L., Stampfer, M.J., Willett, W.C., Eliassen, A.H., Hart, J.E., Chavarro, J.E., Rich-Edwards, J.W. and Zhang, F. (2020) Risk of COVID-19 among Front-Line Health-Care Workers and the General Community: A Prospective Cohort Study. The Lancet Public Health, 5, e475-e483. 
[4] Sen-Crowe, B., McKenney, M. and Elkbuli, A. (2020) Social Distancing during the COVID-19 Pandemic: Staying Home Save Lives. American Journal of Emergency Medicine, 38, 1519-1520. https://doi.org/10.1016/j.ajem.2020.03.063

[5] Grasselli, G., Pesenti, A. and Cecconi, M. (2020) Critical Care Utilization for the COVID-19 Outbreak in Lombardy, Italy: Early Experience and Forecast during an Emergency Response. JAMA, 323, 1545-1546.

https://doi.org/10.1001/jama.2020.4031

[6] Al Ghafri, T., Al Ajmi, F., Anwar, H., Al Balushi, L., Al Balushi, Z., Al Fahdi, F., Al Lawati, A., Al Hashmi, S., Al Ghamari, A., Al Harthi, M., Kurup, P.M., Al Lamki, M., Al Manji, A., Al Sharji, A., Al Harthi, S. and Gibson, E. (2020) The Experiences and Perceptions of Health-Care Workers During the COVID-19 Pandemic in Muscat, Oman: A Qualitative Study. Journal of Primary Care and Community Health, 11, 1-8. https://doi.org/10.1177/2150132720967514

[7] Lai, J., Ma, S., Wang, Y., Cai, Z., Hu, J., Wei, N., Wu, J., Du, H., Chen, T., Li, R., Tan, H., Kang, L., Yao, L., Huang, M., Wang, H., Wang, G., Liu, Z. and Hu, S. (2020) Factors Associated with Mental Health Outcomes among Health Care Workers Exposed to Coronavirus Disease 2019. JAMA Network Open, 3, e203976. https://doi.org/10.1001/jamanetworkopen.2020.3976

[8] Nyangu, I. and Nkosi, Z.Z. (2019) Antiretroviral Therapy Program Accessibility across Lesotho Districts' Primary Health Care Centers. Journal of Public Health and Diseases, $2,7$.

[9] Alhofaian, A., Tunsi, A., Alaamri, M.M., Babkair, L.A., Almalki, G.A., Alsadi, S.M., Alharthi, S.S. and Almarhabi, G.A. (2021) Perception of Heath Care Providers about COVID-19 and Its Vaccination in Saudi Arabia: Cross-Sectional Study. Journal of Multidisciplinary Healthcare, 14, 2557-2563.

https://doi.org/10.2147/JMDH.S327376

[10] Smith, J., Odera, D.N., Chege, D., Muigai, E.N., Patnaik, P., Michaels-Strasser, S., Howard, A.A., Yu-Shears, J. and Dohrn, J. (2016) Identifying the Gaps: An Assessment of Nurses' Training, Competency, and Practice in HIV Care and Treatment in Kenya. Journal of the Association of Nurses in AIDS Care, 27, 322-330. https://doi.org/10.1016/j.jana.2016.01.005

[11] Bhagavathula, A.S., Aldhaleei, W.A., Rahmani, J., Mahabadi, M.A. and Bandari, D.K. (2020) Knowledge and Perceptions of COVID-19 among Health Care Workers: Cross-Sectional Study. JMIR Public Health and Surveillance, 6, 1-9. https://doi.org/10.2196/19160

[12] Türktemiz, H., Ünal, Ö. and Aydin, D.B. (2021) Assessment of Healthcare Professionals' Perceptions and Attitudes towards the COVID-19 Pandemic in Turkey. Work, 69, 1163-1170. https://doi.org/10.3233/WOR-205305

[13] Wang, C., Pan, R., Wan, X., Tan, Y., Xu, L., Ho, C.S. and Ho, R.C. (2020) Imme Diate Psychological Responses and Associated Factors during the Initial Stage of the 2019 Coronavirus Disease (COVID-19) Epidemic among the General Population in China. International Journal of Environmental Research and Public Health, 17, 1729. https://doi.org/10.3390/ijerph17051729

[14] Tao, R., Downs, J., Beckie, T.M., Chen, Y. and McNelley, W. (2020) Examining Spatial Accessibility to COVID-19 Testing Sites in Florida. Annals of GIS, 26, 319-327. https://doi.org/10.1080/19475683.2020.1833365

[15] Wittenberg, E., Goldsmith, J.V., Chen, C., Prince-Paul, M. and Johnson, R.R. (2021) Opportunities to Improve COVID-19 Provider Communication Resources: A Systematic Review. Patient Education and Counseling, 104, 438-451. 
https://doi.org/10.1016/j.pec.2020.12.031

[16] Zhou, S., Huang, T., Li, A. and Wang, Z. (2021) Does Universal Health Insurance Coverage Reduce Unmet Healthcare Needs in China? Evidence from the National Health Service Survey. International Journal for Equity in Health, 20, Article No. 43. https://doi.org/10.1186/s12939-021-01385-7 